\title{
Computational Analysis of Performance and Emissions of a Compression Ignition Engine under various Air Induction Methods
}

\author{
Afaaq Ahmad Mir ${ }^{a}$, M. Marouf Wani ${ }^{b}, *$ \\ ${ }^{a}$ Research Scholar, NIT Srinagar, India, 190006 \\ ${ }^{b}$ Faculty of Engineering, NIT Srinagar, India,190006
}

\begin{abstract}
A computational study on performance and exhaust emissions from a 4-stroke DI CI engine using different air induction methods was carried out. Using AVL Boost IC engine simulation software a model was developed with a Naturally Aspirated (NA) air induction mode, the second model was developed by incorporating a turbocharger (TC) and again a third model was developed by the introduction of a turbocharger along with an intercooler (TCI). The individual effects of all the three air induction methods on the performance and emission of engine were studied and compared. The power output for the engine with TCI was observed to be $7.8 \%$ more than that of an engine with TC, where as it was even greater i-e $20 \%$ more when compared with NA engine. Similar Improved results for torque were also observed in case of an engine with TCI. It was also observed that emissions were higher with TCI followed with TC and NA.
\end{abstract}

Keywords: Air Induction, Turbo-charging, Inter-cooling, performance, Emissions

\section{Introduction}

In the current investigation AVL Boost IC engine simulation software was used to evaluate the performance and emissions of a CI engine with different air induction methods. The Combustion efficiency is significantly dependent on the air induction method adopted in a SI engine or CI engine. Intake air boosting technologies that are used in modern automobiles have achieved significant power gain by compressing intake air to higher density with higher pressures. Comparatively less power output due to lower intake air density in case of naturally aspirated engines limits its use in modern engine technology.[1].

Now-a-days advanced technology of turbocharging in engines is a promising air induction method which substantially boosts the intake air density and hence the power output of an engine by improving its volumetric efficiency. Turbochargers are also called as power boosting devices. A turbocharger consists of a turbine and a compressor wheel which are mounted on the same shaft. The turbine is driven by the hot exhaust gases from the engine cylinders which in turn spins the compressor wheel mounted on the same shaft drawing in ambient air and

${ }^{*}$ Corresponding author. Tel.: 09697911102

E-mail: afaaq_14phd12@nitsri.net

(c) 2015 International Association for Sharing Knowledge and Sustainability

DOI: $10.5383 /$ ijtee.09.01.007 compresses it to high pressures before it enters the intake manifold [2]. Turbochargers have been used in automobiles with different arrangements, auxiliaries and geometry such as simple exhaust turbocharging, steam turbocharging, steamassisted turbocharging [3] Variable Geometry Turbocharger[4] Dual stage Turbocharging [5] Twin-Entry turbocharging [6] etc all of these are effective power boosting air inductions methods. While these power boosting methods increase the air density, higher temperatures are developed in the compressed air due to increased pressure which results in reduction of intake air density. This reduction of air density due to increasing temperature of intake air is considered as turbocharging loss, which is recovered often by using a cooling device called as Intercooler. Intercoolers are used to cool the hot compressed air after it leaves the turbocharger and this process of cooling is nearly isobaric.[7]

In this paper a 1D simulation model for a conventional (Naturally Aspirated) CI engine developed by using AVL Boost with two zone combustion model is presented. Keeping the compression ratio constant, effects of a turbocharger and a turbocharger in combination with an intercooler on the performance and emission of the engine were evaluated. 


\section{Simulation Models}

AVL Boost simulation models of the engines shown in Fig.1 consists of a series of elements that replicates components of an engine. Engine Specification and operating parameters used in Boost simulation code is given in Table.1 and Table.2 below.

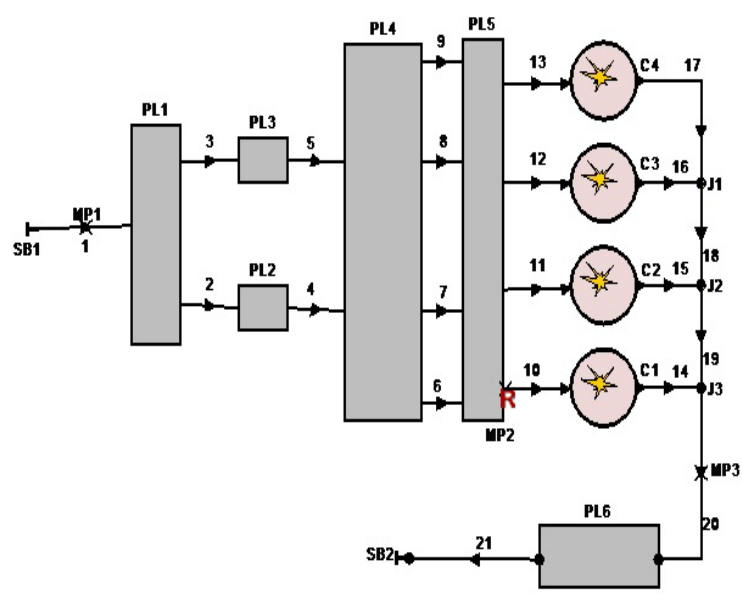

(a) Naturally Aspirated Engine (NA)

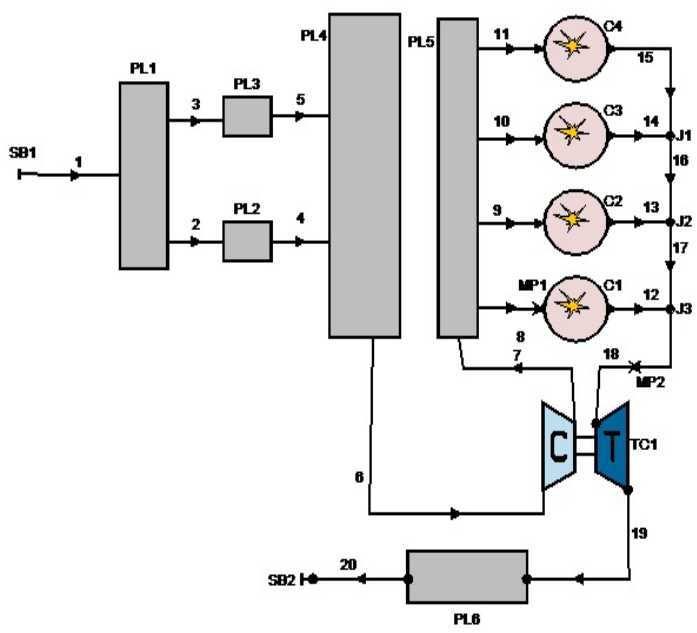

(b) Turbocharged Engine(TC)

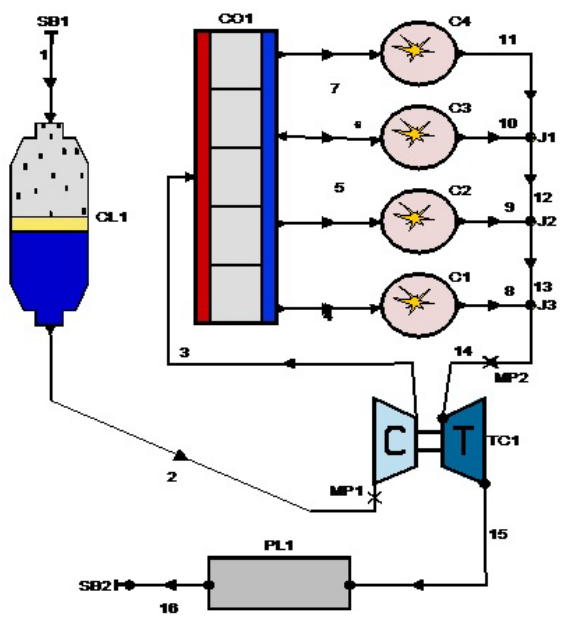

(c) Turbocharged Engine fitted with Intercooler(TCI)

Fig. 1. Various types of engine models used in investigation.
Table 1. Engine Specification

\begin{tabular}{|l|l|}
\hline Bore & $75 \mathrm{~mm}$ \\
\hline Stroke & $78 \mathrm{~mm}$ \\
\hline Compression Ratio & 21 \\
\hline No. of Cylinders & 4 \\
\hline Connecting-Rod Length & $120 \mathrm{~mm}$ \\
\hline Effective blow-by gap & $0.0008 \mathrm{~mm}$ \\
\hline Fuel & Diesel \\
\hline
\end{tabular}

Table 2. Operating Parameters

\begin{tabular}{|l|c|c|}
\hline Engine Speed (rpm) & SOC & A/F \\
\hline $1800-4000$ & -15 & 20 \\
\hline
\end{tabular}

Table.3 Elements of Models

\begin{tabular}{|l|l|}
\hline C & Cylinder \\
\hline CL & Air Cleaner \\
\hline CO & Air Cooler \\
\hline J & Junction \\
\hline MP & Measuring Point \\
\hline PL & Plenum \\
\hline SB & System Boundary \\
\hline $1,2,3 \ldots$ & Pipes \\
\hline
\end{tabular}

Each elements of the models use basic equations to calculate values of various thermodynamic variables. Gas properties in these elements are calculated at each time step with instantaneous composition using solutions of gas dynamic equations. Gas exchange processes in each element are considered one-dimensional. Governing equations used in AVL Boost for one-dimensional processes are given below. First law of thermodynamics is used to calculate the thermodynamic state of cylinder which is in the form

$$
\begin{aligned}
& \frac{d\left(m_{c} \cdot u\right)}{d \alpha}=-p_{c} \cdot \frac{d V}{d \alpha}+\frac{d Q_{F}}{d \alpha}-\sum \frac{d Q_{w}}{d \alpha}-h_{B B} \cdot \frac{d m_{B B}}{d \alpha} \\
& +\sum \frac{d m_{i}}{d \alpha} \cdot h_{i}-\sum \frac{d m_{e}}{d \alpha} \cdot h_{e}-q_{e v} \cdot f \cdot \frac{d m_{e v}}{d t}
\end{aligned}
$$

Variation of mass flowing in and out of the cylinder is calculate as

$\frac{d m_{e}}{d \alpha}=\sum \frac{d m_{i}}{d \alpha}-\sum \frac{d m_{e}}{d \alpha}-\frac{d m_{B B}}{d \alpha}+\frac{d m_{e v}}{d t}$

where,

$\frac{d\left(m_{c} . u\right)}{d \alpha}$ is change of internal energy, $-p_{c} \cdot \frac{d V}{d \alpha}$ is piston work, $\frac{d Q_{F}}{d \alpha}$ is fuel heat input, $\sum \frac{d Q_{w}}{d \alpha}$ is wall heat losses, 
$\frac{d m_{B B}}{d \alpha}$ is blow-by mass flow and $h_{B B} \cdot \frac{d m_{B B}}{d \alpha}$ is enthalpy flow due to blow-by.

Heat transfer to the walls of cylinder is calculated from

$$
Q_{w i}=A_{i} \cdot \alpha_{w} \cdot\left(T_{c}-T_{w i}\right)
$$

For the assessment of heat transfer Woschni model for high pressure cycle is used which is as follows:

$$
\begin{aligned}
\alpha_{w}= & 130 \cdot D^{-0.2} \cdot p_{c}^{0.8} \cdot T_{c}^{-0.53} \\
& {\left[C_{1} \cdot c_{m}+C_{2} \cdot \frac{V_{D} \cdot T_{c, 1}}{p_{c, 1} \cdot V_{c, 1}} \cdot\left(p_{c}-p_{c, 0}\right)\right]^{0.8} }
\end{aligned}
$$

where,

$$
\begin{aligned}
& C_{I}=2.28+0.308 . c_{u} / c_{m} \\
& C_{2}=0.00324 \text { for DI engines } \\
& C_{2}=0.00622 \text { for IDI engines }
\end{aligned}
$$

Combustion process characterization is modeled by direct specification of rate of heat release. For which vibe function is used

$$
\begin{aligned}
& \frac{d x}{d \alpha}=\frac{a}{\Delta \alpha_{c}} \cdot(m+1) \cdot y^{m} \cdot e^{-a \cdot y^{(m+1)}} \\
& d x=\frac{d Q}{Q} \\
& y=\frac{\alpha-\alpha_{0}}{\Delta \alpha_{c}}
\end{aligned}
$$

Combustion process for the engine models studied in this investigation were evaluated for burned zone and unburned zone. For which first law of thermodynamics is applied to the burned charge and unburned charge as follows:

$$
\begin{aligned}
\frac{d\left(m_{b} \cdot u_{b}\right)}{d \alpha}= & -p_{c} \cdot \frac{d V_{b}}{d \alpha}+\frac{d Q_{F}}{d \alpha}-\sum \frac{d Q_{w b}}{d \alpha}+h_{u} \cdot \frac{d m_{b}}{d \alpha} \\
& -h_{B B, b} \cdot \frac{d m_{B B, b}}{d \alpha} \\
\frac{d\left(m_{u} \cdot u_{u}\right)}{d \alpha}= & -p_{c} \cdot \frac{d V_{u}}{d \alpha}-\sum \frac{d Q_{w u}}{d \alpha}-h_{u} \cdot \frac{d m_{B}}{d \alpha} \\
& -h_{B B, u} \cdot \frac{d m_{B B, u}}{d \alpha}
\end{aligned}
$$

index $b$ is for burned zone index $u$ is for unburned zone

One-dimensional gas dynamics in a pipe are described by Euler Equation:

$$
\frac{\delta U}{\delta t}+\frac{\delta F(U)}{\delta x}=S(U)
$$

where, $U$ represents the state vector and $F$ is the flux vector. Right-hand side source term comprises two different source terms:

$$
S(U)=S_{A}(F(U))+S_{R}(U)
$$

where $S_{A}$ is the source caused by axial changes in the pipe cross-section and $S_{R}$ is the source taking into account homogeneous chemical reactions, heat and mass transfer terms between the gas and solid phase, and friction sources.

Evaluation of the gas dynamics in a plenum is very similar to the simulation of the gas exchange process of a cylinder as described by equation (1):

$$
\begin{aligned}
\frac{d\left(m_{p l} \cdot u\right)}{d \alpha}= & -p_{p l} \cdot \frac{d V}{d \alpha}-\sum \frac{d Q_{w}}{d \alpha}+\sum \frac{d m_{i}}{d \alpha} \cdot h_{i} \\
& -\sum \frac{d m_{e}}{d \alpha} h_{e}=\frac{d Q_{\text {reac }}}{d \alpha}
\end{aligned}
$$

For Emission models: NOx, $\mathrm{CO}$ and Soot formation model is based on Pattas and Hafner which uses well know zeldovich mechanism for NOx formation. For $\mathrm{CO}$ and Soot emission estimation Onorati et al and Schubiger et al Models are incorporated respectively. Turbocharger matching is done in AVL Boost using suitable compressor and turbine size for a turbocharger of an engine. The simplified turbocharger model with its three calculation modes (turbine layout, boost pressure and waste gate calculation) helps in this task. $[8,9]$

\section{Results and Discussion}

\subsection{Effects of Engine Speed on Power}

Fig. 2 shows the effect of speed on power of three engine of different air induction configurations. It can be seen from the figure that power increases with the increase in speed for all the three engines which is due to more number of power cycles per unit time.

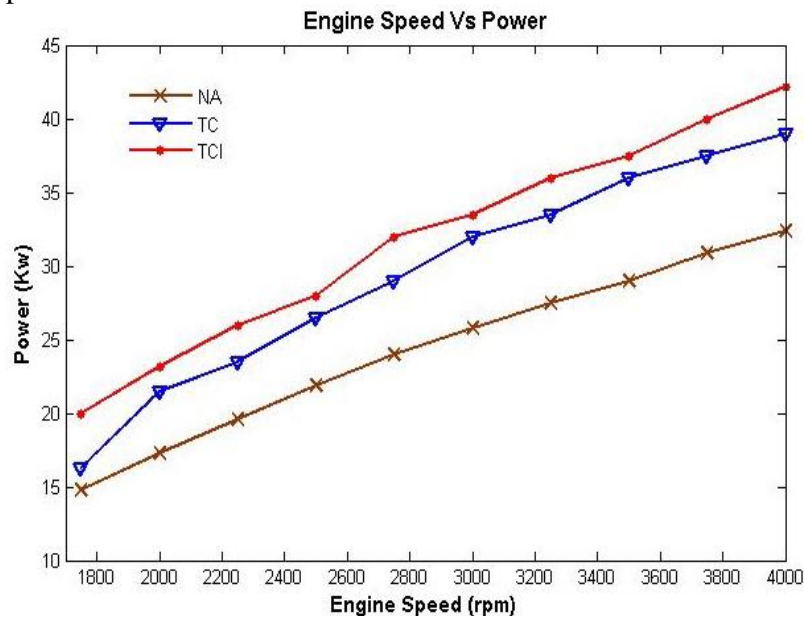

Fig. 2. Effects of Engine Speed on Power

Also, it is apparent from the figure that by incorporating a turbocharger in the same engine there is improved power output compared to Naturally Aspirated one, which is basically due to the compressor of the turbocharger which increases the intake air density in the intake manifold commonly called as 
Pressure Boosting. This increase in boost pressure in turn increases the volumetric efficiency of the engine and hence the power output. While boost pressure increases air density and friction heats air in motion and causes an increase in temperature. This increase in temperature decrease air density. Hence, by incorporating an intercooler with a turbocharger an increase in power output of about 7.8 percent was observed against the one with TC only. As intercooler works as heat exchanger which lowers the temperature of intake air and hence provides more chances of increasing the air density in the intake manifold.

\subsection{Effects of Engine Speed on Torque}

Fig.3 Shows the variation of Torque output of three engines with the varying speed. Like power output of the engine Torque output also depends on the intake air density or volumetric efficiency. Therefore, this gain of torque output of TCI over TC and TC over NA is obvious.

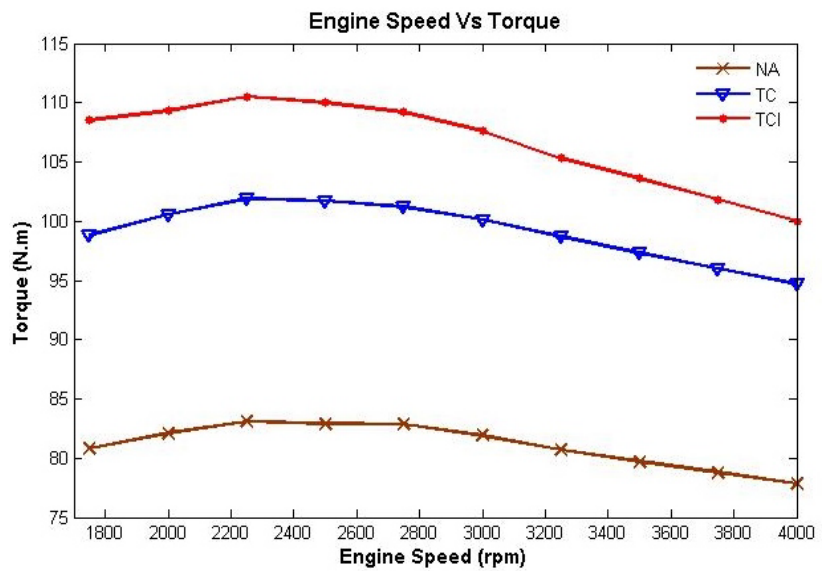

Fig. 3. Effects of Engine Speed on Torque

\subsection{Effects of Engine Speed on Bsfc}

Fig.4 Shows the trend of Bsfc with varying engine speed. Bsfc is defined as mass flow rate of fuel per unit power output.

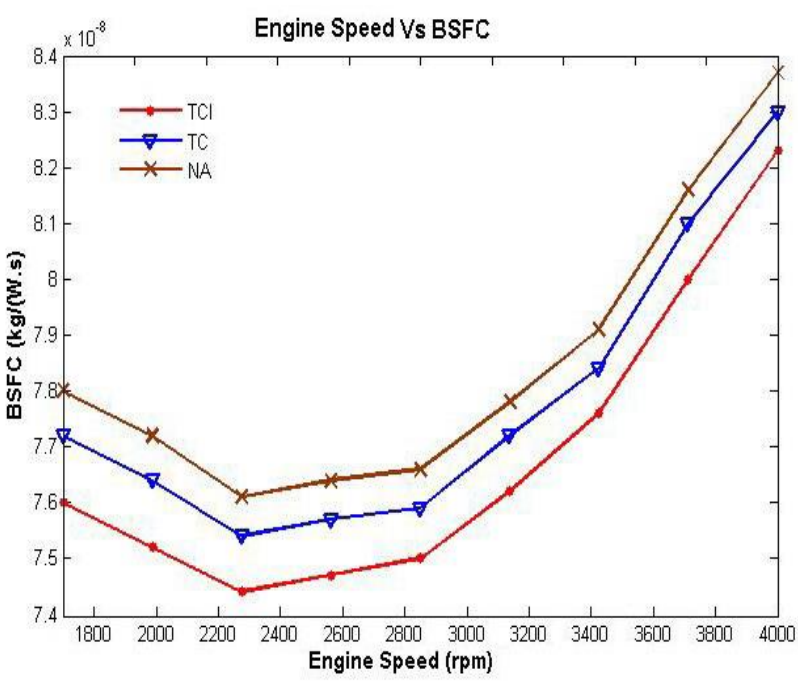

Fig. 4. Effects of Engine Speed on Bsfc
The bsfc first decreases with increase in engine speed as the increasing power remains a dominating factor. Later the bsfc increase with increasing engine speed as the mass flow rate of fuel becomes more dominating as compared to increase in engine speed, keeping the A/F ratio same. Since the power developed is more in case of TCI followed by TC and NA modes. So, the bsfc is lower with TCI followed by TC and NA.

\subsection{Effects of Engine Speed on CO Emission}

Fig.5 shows effects of engine speed on the $\mathrm{CO}$ emissions. Increasing level of $\mathrm{CO}$ with the engine speed is due to more number of power cycles per unit time and less time availability for complete combustion at higher speeds. The $\mathrm{CO}$ emissions are more with TCI, while as lesser in case of TC and NA modes due to inferior combustion characteristics in TCI mode as compared to TC mode which is followed by NA mode in a decreasing trend.

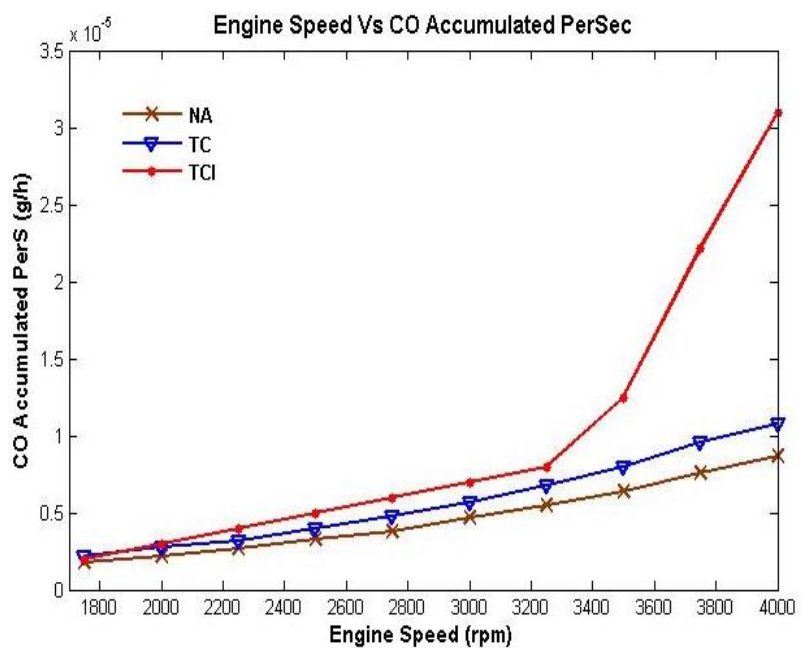

Fig. 5. Effects of Engine Speed on CO Emissions

\subsection{Effects of Engine Speed on Soot Emissions}

Fig.6 Shows the effects of engine speed on Soot formation. Increasing concentration of soot is due to rich mixture combustion when fuel injection is maximized to supply more power at higher speeds.

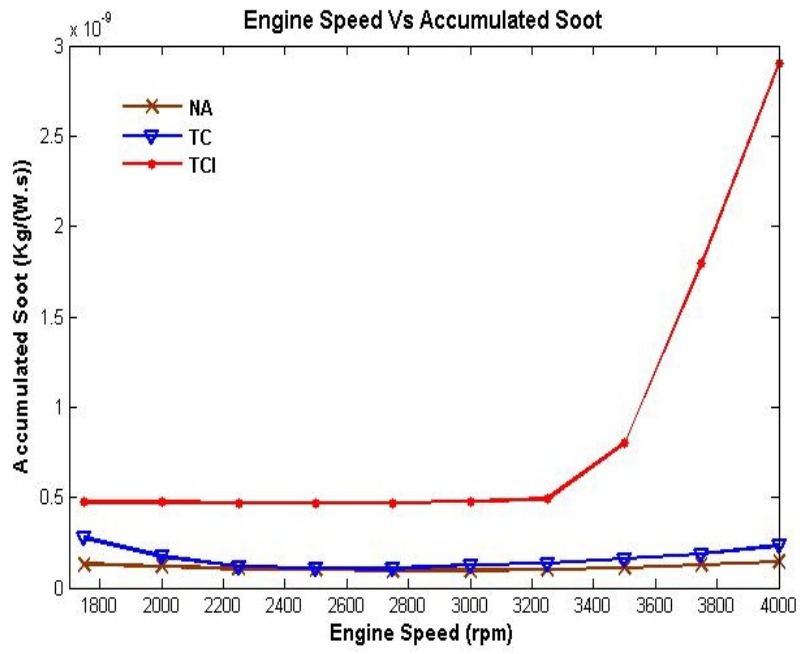

Fig. 6. Effects of Engine Speed on Soot Emissions 
Due to better combustion in the same displacement volume in the NA mode followed by inferior combustion in TC and TCI modes the soot emissions are more in TCI, while its less in TC and lesser in NA. This is due to decreasing swirl, squish and turbulence in TCI, TC and NA respectively for the same displacement volume.

\subsection{Effects of Engine Speed on NOx Emissions}

NOx formation in engines depends on two factors, higher combustion temperatures and availability of excessive air in combustion chamber. In Fig.7 increasing level of NOx for all the three modes is due increasing number of power cycles with engine speed which necessitates raised mass flow rate of fuel and air. However, higher NOx level in TCI mode followed by TC and NA mode is due the fact that fuel flow rate increases at a much lower rate than the air flow rate when intake air pressure is increased[10] and high temperature generation shown in Fig.8.

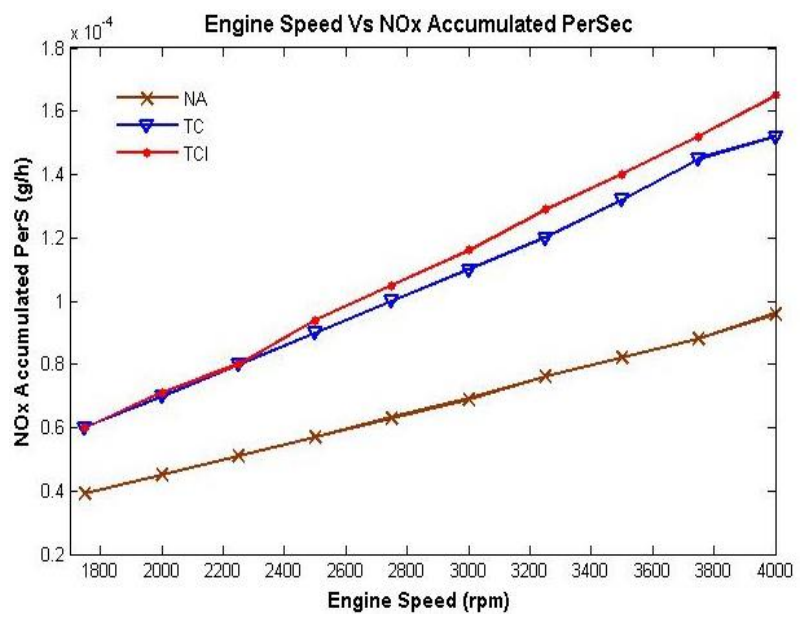

Fig. 7. Effects of Engine Speed on NOx Emissions

\subsection{Effects of Engine Speed on Exhaust Gas Temperature (EGT)}

Fig.8 Shows the effects of engine speed on Exhaust gas temperature.

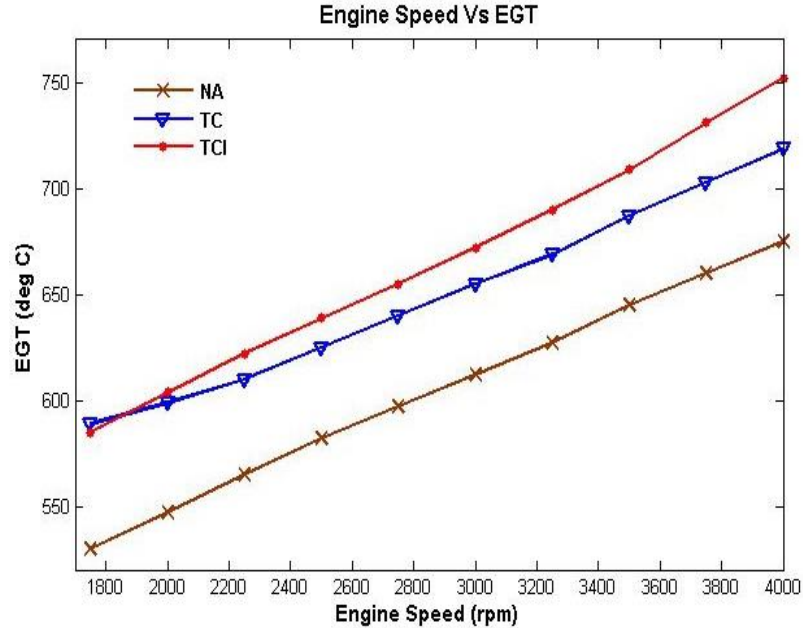

Fig. 8. Effects of Engine Speed on EGT
Rising levels of EGT with increasing engine speed and intake air pressure( for TCI followed by TC and NA) can be explained as more fuel is burnt at higher engine speeds and higher power outputs while keeping the $\mathrm{A} / \mathrm{F}$ ratio constant.

\section{Conclusion}

The particular air induction method has significant impact on engine performance as well on engine emissions. Power output of TCI mode is 7.8 percent more than an engine with TC and 20 percent more than a naturally aspirated engine. Similar trends were also observed for torque output. The NOx, CO and soot emissions were observed higher with power boosting methods (TCI followed by TC and NA).

\section{Nomenclature}

$m_{c} \quad$ Mass in Cylinder

$\boldsymbol{u} \quad$ Specific internal energy

$p_{c} \quad$ Cylinder pressure

V Cylinder Volume

$Q_{F} \quad$ Fuel Energy

$Q_{w} \quad$ Wall heat loss

$\alpha \quad$ Crank angle

$h_{B B} \quad$ Enthalpy Blow-by

$d m_{i} \quad$ Mass element owing into the cylinder

$d m_{e} \quad$ Mass element owing out of the cylinder

$h_{i} \quad$ Enthalpy of in-owing mass

$h_{e v} \quad$ Enthalpy of out-owing mass

$q_{e v} \quad$ Evaporation heat of the fuel

$f \quad$ Fraction of evaporation heat from the cylinder charge

$m_{e v} \quad$ Evaporating fuel

$Q_{w i} \quad$ Wall heat flow (cylinder head, piston, liner)

$A_{i} \quad$ Surface area (cylinder head, piston, liner)

$\alpha_{w} \quad$ Heat-transfer coefficient

$T_{c} \quad$ Gas temperature in the cylinder

$T_{w i} \quad$ Wall temperature

D Cylinder Bore

$C_{m} \quad$ Mean piston speed

$C_{u} \quad$ Circumferential velocity

$V_{D} \quad$ Displacement per cylinder

$p_{c, o} \quad$ Cylinder pressure of the motored engine

$T_{c, 1} \quad$ Temperature in the cylinder at inlet valve closing 


$\begin{array}{ll}p_{c, 1} & \text { Pressure in the cylinder at IVC } \\ Q & \text { Total fuel heat input } \\ Q_{\text {reac }} & \text { Enthalpy source due to chemical reaction } \\ \alpha_{o} & \text { Start of combustion } \\ \Delta \alpha_{c} & \text { Combustion duration } \\ m & \text { Shape parameter } \\ a & \text { vibe parameter } a=6.9 \text { for complete combustion }\end{array}$

\section{Acknowledgment}

The authors are thankful to AVL India and AVL Austria for providing free license of BOOST IC engine simulation software to Mechanical Engineering Department, NIT Srinagar, India

\section{References}

[1] Mustafa Canakci, " An Experimental study for the effects of boost pressure on the performance and exhaust emissions of a DI-HCCI gasoline engine." Fuel 87 (2008) 1503-1514.

[2] P.S. Ranjit, Narayan Khatri, Mukesh Saxena, Avanish K Tiwari," Studies on influence of Turbocharger on Performance Enhancement and Reduction in Emissions of an IDI CI engine". Volume:3, Issue : 5, May 2014 ISSN No 2277-8160.
[3] Jianqin Fu, Jingping Liu, Yong Wang, Banglin Deng, Yanping Yang, Renhua Feng, Jing Yang,"A comparative study on various turbocharging approaches based on IC engine exhaust gas energy recovery". Applied Energy 113 (2014) 248257.

[4] Yue-Yun Wanga, Ibrahim Haskara, Oded Yaniv," Quantitative feedback design of air and boost pressure control system for turbocharged diesel engines". Control Engineering-Practice 19 (2011) 626637.

[5] Choi, C., Kwon, S., and Cho, S.," Development of Fuel Consumption of Passenger Diesel Engine with 2 Stage Turbocharger". SAE paper 2006-01-0021.

[6] A. Kusztelan, D. Marchant, Y. Yao, Y. Wang, S. Selcuk, A. Gaikwad," Increases in Low Speed Response of an IC Engine using a Twin-entry Turbocharger" Proceedings of the World Congress on Engineering 2012 Vol III,WCE 2012, July 4 - 6, 2012, London, U.K

[7] Turbocharging and Supercharging, Published by: Janeth Tepan on Mar 13, 2013, Chaper19, page no. $325,326$.

[8] AVL Boost Theory Manual, version 2009.

[9] AVL Boost User's guide Manual, version 2009.

[10] John B. Heywood," Internal combustion engine fundamentals", page no. 248,249,250 and 875 . 